\title{
Effect of Operating Conditions on Inclusion of Die Steel during Electroslag Remelting
}

\author{
Gang DU, Jing LI and Zhong-Bing WANG \\ State Key Laboratory of Advanced Metallurgy, University of Science and Technology Beijing (USTB), Beijing, 100083 P.R. \\ China.
}

(Received on July 24, 2017; accepted on August 30, 2017; J-STAGE Advance published date: October $17,2017)$

\begin{abstract}
The current paper focuses on the effect of different operating conditions on the content of inclusions and cleanliness of remelting ingots. For these investigations, eight ingots were remelted with two slag amount and with two current intensity under otherwise comparable remelting conditions. A twodimensional (2D) coupled mathematical model was employed to simulate the velocity field, solidification and inclusion motion for a system of electrode, slag and ingot in electroslag remelting (ESR) processes, to reveal the inclusion removal mechanism. The results showed that the content of large-sized inclusions in ESR ingot was decreased by approximately $66.18 \%$ when the slag amount was increased from 17.85 $\mathrm{kg}$ to $20.50 \mathrm{~kg}$. Because of the increase of slag amount, the metal and slag flow faster and the maximal velocity increases by $10.3 \%$, thus there is an increasing trend in trajectories of inclusions (i.e., inclusion motion) in slag pool resulted from the stronger natural convective flow, which is beneficial for the inclusion removal. When the average current was increased from $4 \mathrm{kA}$ to $5 \mathrm{kA}$, the content of large-sized inclusions in ESR ingot was decreased by approximately 51.38\%. Because of the increasing of current, the flow in the middle of the slag pool becomes stronger and the maximal downward velocity increases by $2.7 \%$, thus there is an increasing trend in the renewal rate of the metal film surface due to the stronger washing by slag flow, which can promote the inclusion removal.
\end{abstract}

KEY WORDS: electroslag remelting; inclusion content; cleanliness; slag amount; current; numerical simulation; H13 die steel.

\section{Introduction}

The increasing demand for producing high-quality steel has led to the stringent control of steel cleanliness, including oxygen content and inclusions, which has been attracting great attention in recent years. ${ }^{1-3)}$ Non-metallic inclusions in steel are often the initiation source of fatigue crack which seriously affect the service life of steel, particularly the existence of large-sized inclusions are extremely detrimental to fatigue life and service performance despite their limited numbers. ${ }^{4-6)}$ Electroslag remelting (ESR) is one of the most important and effective ways to control the cleanliness and solidification structure of steel. ${ }^{7,8)}$

ESR process is caused by means of an alternating current (AC) or a direct current (DC) which flows through the highresistivity slag pool from the electrode to the ingot, thus generating Joule heating in the electrode and slag. The Joule heating at the electrode periphery is significantly greater than that in the center, owing to the higher current density concentrated at the electrode periphery induced by the skin effect; ${ }^{9,10)}$ in addition, the maximum of Joule heating is at the electrode/slag interface region around the electrode tip,

\footnotetext{
* Corresponding author: E-mail: singsundu@sina.com

DOI: http://dx.doi.org/10.2355/isijinternational.ISIJINT-2017-429
}

which provides the necessary energy to melt consumable electrode. During the ESR process, the consumable electrode tip immersed in slag with a high temperature will melt, and then thin liquid metal films come into being when the thermal energy supplied by Joule heating accumulated to a certain degree. The newly formed thin liquid metal film on the surface of electrode tip is washed away driven by the Lorentz force and the gravity force and gradually accumulates on the nose of the electrode tip. When the drop on the nose of the electrode tip reaches the critical size (normally 1 to $10 \mathrm{~mm}$ in diameter ${ }^{11)}$ ), necking effect will happen leading to the formation of small droplets. At last, the droplet will detach from the electrode tip when it reach a certain mass, and thereafter travel through the slag pool into the metal pool in the ways of individual droplets or the continuous stream of liquid steel. Thus, the molten steel is refined by both physical and chemical ways during its interaction with the molten slag at the molten steel-slag interface. ${ }^{11,12)}$

Variety of factors impact the cleanliness level of ESR ingot including steel quality and grade of the consumable electrode, remelting atmosphere, slag amount and its composition, remelting current, furnace voltage, cooling rate, remelting rate, input power, filling ratio, magnetic field, etc., in which the operating conditions is a critical aspect to improve steel cleanliness. ${ }^{13)}$ Extensive research studies 
have been performed to investigate the effect of operating conditions to the steel cleanliness during ESR process. ${ }^{14-17)}$ ESR Operating conditions have been gradually modified to control the steel cleanliness to improve the ingot quality in recent years. ${ }^{14,15)}$ Dong et al. ${ }^{16)}$ studied the effect of slag composition on the inclusions in ESR ingots based on the experiment of interaction between slag and metal and electroslag remelting. Results indicate that multi-component slag has better capacity for controlling the amount of inclusions than classical slag. Paar et al. ${ }^{17)}$ investigated the effect of electrical parameters (i.e., DC polarities and low frequency $\mathrm{AC}$ power supplies) on the type and content of inclusions in ESR ingot. Results show that the cleaning effect of both DC polarities (cathodic and anodic) is more pronounced than the one with low frequency AC power supply and the cathodic DC polarity exhibits better cleanliness levels than the anodic one. In view of the inherent difficulties in observing and measuring the melting, fluid flow and solidification process during the complicated ESR process due to the presence of high temperature, strong electromagnetic field and opaque materials, there is, however, less research about the effect of ESR operating conditions (i.e., slag amount and remelting current) on inclusion content and removal ratio of inclusions, especially those large-sized inclusions during electroslag remelting of $\mathrm{H} 13$ die steel.

As known, the large-sized inclusions are extremely detrimental to steel quality despite their limited population. In some circumstances, even only one single large-sized inclusion in a whole steel heat can induce a catastrophic disaster. To this end, the content of these detrimental largesized inclusions must be carefully controlled. Therefore, more attention should be given to the removal ratio and content of large-sized inclusions, based on more detailed analysis throughout the ESR process as much as possible. However, the problem lies in the fact that the population of these scarcely distributed large-sized inclusions is limited. Hence, it is extremely difficult to detect these catastrophic large-sized inclusions with conventional metallographic examination methods such as optical microscopy detection and image analysis due to the limited analysis area. This is especially the case for the second refined ESR ingot, where these kinds of large-sized inclusions can be occasionally found. Therefore, additional determination should be introduced to analyze the large-sized inclusion content in the steel for tackling this problem, besides conventional metallographic examination methods.

The main purpose of the current investigation is, therefore, to investigate the effect of ESR operating conditions (i.e., slag amount and current) on inclusions in H13 steel and improve the steel cleanliness and ingot quality. The mechanisms of inclusion removal were also discussed, based on experimental results and theoretical analysis. With the help of electrolytic extraction method, a very large volume of inspection (several hundred thousands of $\mathrm{mm}^{3}$ ) of inclusions was investigated, to realize a better and deeper understanding of those catastrophic large-sized inclusions for more precise and effective control of them. In addition, a two-dimensional model (MeltFlow) was also employed to reveal the influence mechanisms of slag amount and current on inclusion removal during ESR process.

\section{Experimental}

\subsection{Experimental Procedure}

The H13 electrode materials were produced by using an $\mathrm{MgO}$ crucible of a induction melting furnace. After induction melting, the molten steel was cast into ingots, which were thereafter used as consumable electrodes in ESR experiments. The chemical composition of the produced H13 consumable electrode is shown in Table 1. The produced ingots were divided into two groups (i.e., $1 \mathrm{E}$ and $2 \mathrm{E}$ ) and designated as 1E-1, 1E-2, 1E-3, 1E-4, 2E-1, 2E-2, 2E-3, and $2 \mathrm{E}-4$, respectively.

The schematic diagram of experimental apparatus is shown in Fig. 1. The inner diameter and outer diameter of water-cooled copper mold is $300 \mathrm{~mm}$ and $335 \mathrm{~mm}$ respectively. The length of water-cooled copper mold is 1500 $\mathrm{mm}$. The remelting processes were conducted in the watercooled copper mold, fixed on a similarly cooled copper baseplate. The water flow preasure in the mold and baseplate was about $0.6 \mathrm{Mpa}$ during remelting.

The individual experimental condition for each experiment is summarized in Table 2. In order to investigate the

Table 1. Chemical composition of the H13 consumable electrode (mass\%).

\begin{tabular}{ccccccccccc}
\hline $\mathrm{C}$ & $\mathrm{Si}$ & $\mathrm{Mn}$ & $\mathrm{Cr}$ & $\mathrm{Mo}$ & $\mathrm{V}$ & $\mathrm{Ni}$ & $\mathrm{P}$ & $\mathrm{S}$ & $\mathrm{Al}$ & $\mathrm{Cu}$ \\
\hline 0.42 & 1.20 & 0.32 & 4.59 & 1.20 & 0.85 & 0.16 & 0.025 & 0.008 & 0.025 & 0.11
\end{tabular}

Table 2. Experimental conditions in each ESR experiment.

\begin{tabular}{|c|c|c|c|c|c|}
\hline Group & $\begin{array}{l}\text { Exp. } \\
\text { No. }\end{array}$ & $\begin{array}{l}\text { Ingot } \\
\text { No. }\end{array}$ & $\begin{array}{c}\text { Slag amount/ } \\
\text { kg }\end{array}$ & $\begin{array}{c}\text { Current/ } \\
\text { kA }\end{array}$ & Comments \\
\hline \multirow[t]{4}{*}{$1 \mathrm{~T}$} & $1 \mathrm{~T}-1$ & 1ESR-1 & 17.85 & $3.5-4.5$ & \multirow{2}{*}{$\begin{array}{l}\text { To study the } \\
\text { influence of slag } \\
\text { amount. }\end{array}$} \\
\hline & $1 \mathrm{~T}-2$ & 1ESR-2 & 20.50 & $3.5-4.5$ & \\
\hline & $1 \mathrm{~T}-3$ & 1ESR-3 & 20.50 & $3.5-4.5$ & \multirow{2}{*}{$\begin{array}{l}\text { To study the } \\
\text { influence of } \\
\text { current. }\end{array}$} \\
\hline & $1 \mathrm{~T}-4$ & 1ESR-4 & 20.50 & $4.5-5.5$ & \\
\hline \multirow[t]{4}{*}{$2 \mathrm{~T}$} & $2 \mathrm{~T}-1$ & 2ESR-1 & 17.85 & $3.5-4.5$ & \multirow{2}{*}{$\begin{array}{l}\text { To study the } \\
\text { influence of slag } \\
\text { amount. }\end{array}$} \\
\hline & $2 \mathrm{~T}-2$ & 2ESR-2 & 20.50 & $3.5-4.5$ & \\
\hline & $2 \mathrm{~T}-3$ & 2ESR-3 & 20.50 & $3.5-4.5$ & \multirow{2}{*}{$\begin{array}{l}\text { To study the } \\
\text { influence of } \\
\text { current. }\end{array}$} \\
\hline & $2 \mathrm{~T}-4$ & 2ESR-4 & 20.50 & $4.5-5.5$ & \\
\hline
\end{tabular}

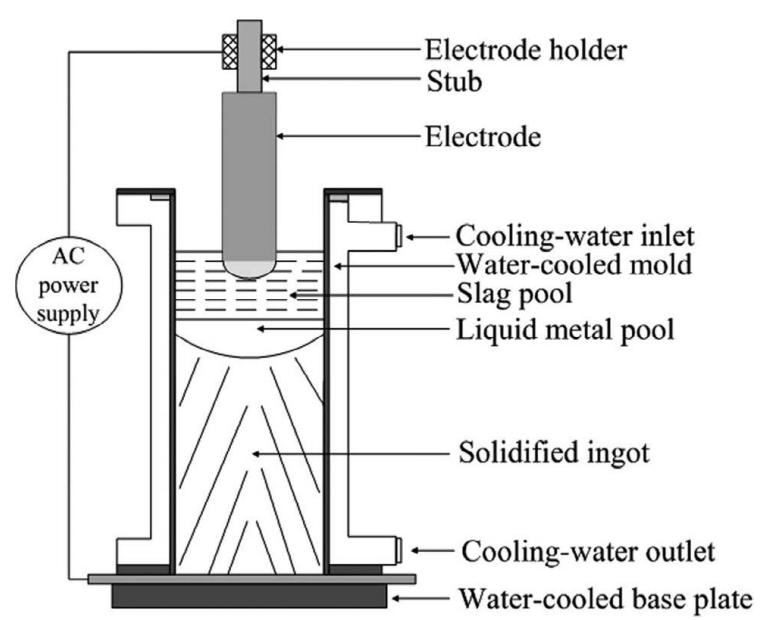

Fig. 1. Schematic diagram of the electroslag remelting. 
effect of operating conditions on the steel cleanliness of ESR ingot, eight experiments in two groups (i.e., $1 \mathrm{~T}$ and $2 \mathrm{~T})$ were conducted with two slag amount $(17.85 \mathrm{~kg}$ and $20.50 \mathrm{~kg}$ ) and two current intensity (3.5-4.5 kA and 4.5-5.5 $\mathrm{kA}$ ) under otherwise comparable remelting conditions. The electrodes in group $2 \mathrm{~T}$ can be regarded as almost identical to group $1 \mathrm{~T}$. The premelted slag (65 mass pct $\mathrm{CaF}_{2}, 30$ mass pet $\mathrm{CaO}, 5$ mass pet $\mathrm{Al}_{2} \mathrm{O}_{3}$ ) was roasted at $500^{\circ} \mathrm{C}$ in a dry box for at least 5 hours to remove the moisture in slag before the ESR experiment. All the electrode were remelted without a protective atmosphere.

After electroslag remelting, the produced ESR ingots in experiments $1 \mathrm{~T}-1,1 \mathrm{~T}-2,1 \mathrm{~T}-3,1 \mathrm{~T}-4,2 \mathrm{~T}-1,2 \mathrm{~T}-2,2 \mathrm{~T}-3$, and 2T-4 were designated as 1ESR-1, 1ESR-2, 1ESR-3, 1ESR4, 2ESR-1, 2ESR-2, 2ESR-3, and 2ESR-4, respectively.

\subsection{Inclusion Analysis}

The small steel samples of $15 \mathrm{~mm} \times 15 \mathrm{~mm} \times 15 \mathrm{~mm}$ that were taken from 1ESR-1, 1ESR-2, 1ESR-3, 2ESR-1, 2ESR-2 and 2ESR-3 were prepared for inclusion analysis, respectively. Statistical analysis was conducted on the number and size ditribution of microscopic inclusions through metallographic examination (i.e., optical microscopy and image analysis). Cleanliness index $(I)$ was introduced to comprehensively assess the content of non-metallic inclusions in steel, which is defined as follows: ${ }^{18)}$

$$
I=\frac{\sum_{i=1}^{k}\left(d_{i} \times n_{i}\right)}{B \cdot S \cdot N}
$$

where $B$ is the equivalent diameter of inclusions; $I$ is the cleanliness index, i.e., the number of inclusions with equivalent diameter of $B$ per unit area in sample; $d_{i}$ is the average diameter of inclusions in different size ranges (in radius) of $0-2.5 \mu \mathrm{m}, 2.5-5 \mu \mathrm{m}, 5-10 \mu \mathrm{m}$ and $10-15 \mu \mathrm{m}, \mathrm{i}=1$, $2,3 \ldots ; n_{i}$ is the number of inclusion in each size range, $\mathrm{i}=$ $1,2,3 \ldots ; N$ is the number of observation field, and fifty view fields in each steel sample were randomly selected to analyze the size and number of inclusions in different size ranges by an image analyzer; $S$ is the total area of a single observation field.

In particular, to find large-sized inclusions, the big steel samples (Diameter: $50 \mathrm{~mm}$, Length: $150 \mathrm{~mm}$ ) were taken from the consumable electrode and ESR ingot for investigation. Electrolytic extraction method was performed to reveal the individual large-sized inclusions with size larger than 50 $\mu \mathrm{m}$ in steel. The big steel sample was immersed in electrolyte (i.e., $\mathrm{FeSO}_{4}$ and $\mathrm{FeCl}_{2}$ solution), and then electrolyzed with the applied anode current less than 7 A. Stainless steel slice was taken as cathode. The temperature of electrolyte was maintained below $35^{\circ} \mathrm{C}$ during electrolysis. The description of the electrolytic extraction method was also described in detailed elsewhere. ${ }^{4,19)}$ After steel matrix dissolved in solution, the remaining slimes was collected into a suspended bag, and then washed. Then, the nonmetallic inclusions which remain in the slimes were elutriated with ethanol, and then collected and analyzed for the weight by Electronic balance.

\section{Numerical Simulation}

Figure 2 shows the mesh model at the initial state and the simplified calculation flowchart of the coupled Meltflow mathematical model used in the current work. The main physical properties, geometrical and operating conditions used in the simulation are shown in Table 3. The data used for the simulation are mainly the thermophysical properties of slag and metal, the geometry of the furnace (i.e., slag, ingot, electrode, and mold) and the operating conditions (i.e., the electric current profiles and power input). Table 4 shows the particle conditions used in the simulation. The particle conditions used in the simulation are mainly the the size, relative density and initial arrangement of particle conditions. All thermophysical properties were compared and performed with information reported in the literature and adjusted by comparison of the experiment. A two-dimensional commercial software (MeltFlow) was employed to simulate the velocity fields, solidification and inclusion motion for a system of electrode, slag and ingot in
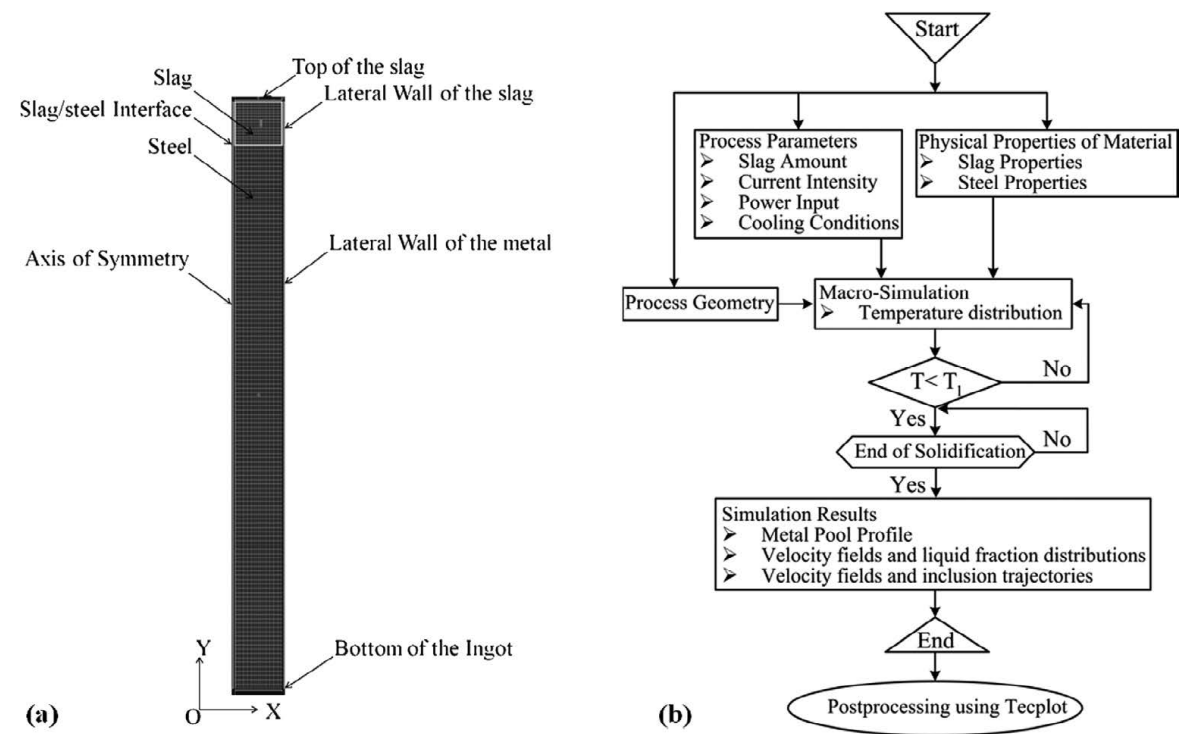

Fig. 2. (a) Mesh mode at the initial state used in the current work (b) simplified calculation flowchart of the coupled Meltflow mathematical model. 
Table 3. Physical properties, geometrical and operating conditions of the current ESR system.

\begin{tabular}{cc}
\hline Parameter & Value \\
\hline Electrode (diameter/height), $\mathrm{m}$ & $0.25 / 0.6$ \\
Ingot (diameter/height), $\mathrm{m}$ & $0.32 / 1.5$ \\
Slag (diameter/height), $\mathrm{m}$ & $0.32 / 0.080,0.091,0.190$ \\
Slag (weight), $\mathrm{kg}$ & $17.85 / 20.5 / 40$ \\
Current amplitude, $\mathrm{KA}$ & $4,5,10$ \\
Voltage, $\mathrm{V}$ & 50 \\
Frequency, $\mathrm{Hz}$ & 50 \\
Electric conductivity of ingot, $\sigma_{\mathrm{m}}, \Omega^{-1} \mathrm{~m}^{-1}$ & $9.215 \times 10^{5}$ \\
Electric conductivity of slag, $\sigma_{\mathrm{s}}, \Omega^{-1} \mathrm{~m}^{-1}$ & 220 \\
Density of electrode, $\mathrm{kg} / \mathrm{m}^{3}$ & 7800 \\
Density of slag, $\mathrm{kg} / \mathrm{m}^{3}$ & 2790 \\
Density of ingot, $\mathrm{kg} / \mathrm{m}^{3}$ & 7800 \\
\hline
\end{tabular}

Table 4. Particle conditions used in the simulation.

\begin{tabular}{ccl}
\hline Size, $\mathrm{mm}$ & $\begin{array}{c}\text { Relative density, } \\
\rho_{\mathrm{p}} / \rho_{\mathrm{m}}\end{array}$ & \multicolumn{1}{c}{$\begin{array}{c}\text { Initial arrangement of } \\
\text { particle conditions }\end{array}$} \\
\hline $\begin{array}{c}0.1,0.3,0.5, \\
0.7,5.0\end{array}$ & $\begin{array}{c}\text { Particles originating at three uni- } \\
1.16,2.05,1.0,\end{array}$ & $\begin{array}{l}\text { formly spaced locations in the metal } \\
\text { pool under the electrode shadow just } \\
\text { below slag-metal interface }\end{array}$ \\
\hline
\end{tabular}

electroslag remelting processes. The theories and details for the computer simulation model have been described in the work $^{20,21)}$ by Kanchan Kelker who developed the software "Meltflow". This program has been applied for the analysis and simulation of the microstructural characteristics with different alloys and process conditions. ${ }^{20,22)}$

\section{Results and Discussions}

\subsection{Chemical Compositions of the Inclusions}

In order to determine the chemical compositions of largesized inclusions, the collected large-sized inclusions were detected by using scanning electron microscopy and energy dispersive spectroscopy (SEM-EDS). Figure 3 shows the SEM image and EDS analysis results of the large-sized inclusions observed in the ESR ingot. Table 5 shows the chemical compositions of inclusions. Four types of inclusions were detected in the ESR ingot. The large-sized inclusions observed in ESR ingot are mainly $\mathrm{CaO}-\mathrm{SiO}_{2}-$ $\mathrm{MgO}-\mathrm{Al}_{2} \mathrm{O}_{3}-\mathrm{TiO}_{2}$ and $\mathrm{CaO}-\mathrm{SiO}_{2}-\mathrm{Al}_{2} \mathrm{O}_{3}$. Meanwhile, a few $\mathrm{SiO}_{2}-\mathrm{MgO}-\mathrm{Al}_{2} \mathrm{O}_{3}$ and $\mathrm{CaO}-\mathrm{SiO}_{2}-\mathrm{MgO}-\mathrm{Al}_{2} \mathrm{O}_{3}$ inclusions were found.

\subsection{Effect of Slag Amount on the Content and Removal of Inclusion}

The effect of slag amount on the content of large-sized inclusions in ESR ingots and their removal ratio are shown in Fig. 4. It is clear that: (i) in the case of the remelting performed with the adding of increased amount of slag (Exp. No. 1T-2), the content of large-sized inclusion can be reduced by $75.77 \%$ from the original inclusion content, i.e., $2.27 \mathrm{mg} / 10 \mathrm{~kg}$, in the ESR ingot 1ESR-1 (Exp. No. 1T-1)

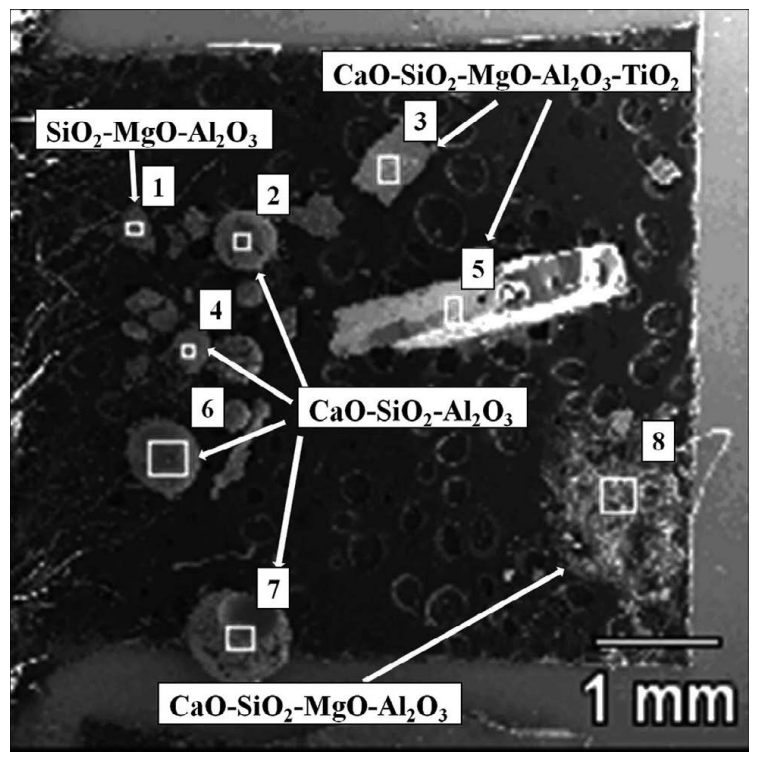

Fig. 3. SEM image and EDS analysis results of large-sized inclusions observed in ESR ingot.

Table 5. Chemical compositions of large-sized inclusions (mass\%).

\begin{tabular}{ccrrrrc}
\hline No. & $\mathrm{Mg}$ & $\mathrm{Al}$ & $\mathrm{Si}$ & $\mathrm{Ca}$ & $\mathrm{Ti}$ & $\mathrm{O}$ \\
\hline 1 & 2.0 & 5.1 & 27.5 & - & - & 65.5 \\
2 & - & 1.7 & 45.4 & 1.1 & - & 51.8 \\
3 & 0.8 & 2.5 & 10.7 & 4.0 & 19.7 & 62.4 \\
4 & - & 11.9 & 27.8 & 6.1 & - & 54.1 \\
5 & 1.0 & 3.5 & 12.3 & 3.8 & 23.8 & 55.5 \\
6 & - & 12.1 & 30.8 & 10.0 & - & 47.1 \\
7 & - & 10.0 & 24.7 & 10.9 & - & 54.5 \\
8 & 1.0 & 7.0 & 33.0 & 2.5 & - & 56.5 \\
\hline
\end{tabular}

to $0.55 \mathrm{mg} / 10 \mathrm{~kg}$ in the ESR ingot 1ESR-2 (Exp. No. 1T-2); (ii) in the case of the remelting performed with the adding of increased amount of slag (Exp. No. 2T-2), the content of large-sized inclusion can be reduced by $56.59 \%$ from the original inclusion content, i.e., $2.58 \mathrm{mg} / 10 \mathrm{~kg}$, in the ESR ingot 2ESR-1 (Exp. No. 2T-1) to $1.12 \mathrm{mg} / 10 \mathrm{~kg}$ in the ESR ingot 2ESR-2 (Exp. No. 2T-2). It was confirmed on the basis of experimental results that the large-sized inclusions content of H13 ESR ingot can be reduced by about $66.18 \%$ by increasing the slag amount from $17.85 \mathrm{~kg}$ to $20.50 \mathrm{~kg}$.

Figure 5 shows the effect of slag amount on cleanliness index of ESR ingots. It is clear that: (i) in the case of the remelting performed with the adding of increased amount of slag (Exp. No. 1T-2), the cleanliness index of steel can be reduced by $18.70 \%$ from the original cleanliness index, i.e., $12.03 \mathrm{ind} \cdot \mathrm{mm}^{-2}$, in the ESR ingot 1ESR-1 (Exp. No. 1T-1) to 9.78 ind $\cdot \mathrm{mm}^{-2}$ in the ESR ingot 1ESR-2 (Exp. No. 1T-2); (ii) in the case of the remelting performed with the adding of increased amount of slag (Exp. No. 2T-2), the cleanliness index of steel can be reduced by $15.60 \%$ from the original cleanliness index, i.e., $11.35 \mathrm{ind} \cdot \mathrm{mm}^{-2}$, in the ESR ingot 2ESR-1 (Exp. No. 2T-1) to 9.58 ind $\cdot \mathrm{mm}^{-2}$ in the ESR ingot 2ESR-2 (Exp. No. 2T-2). It was confirmed on the basis of experimental results that the cleanliness index of H13 ESR 


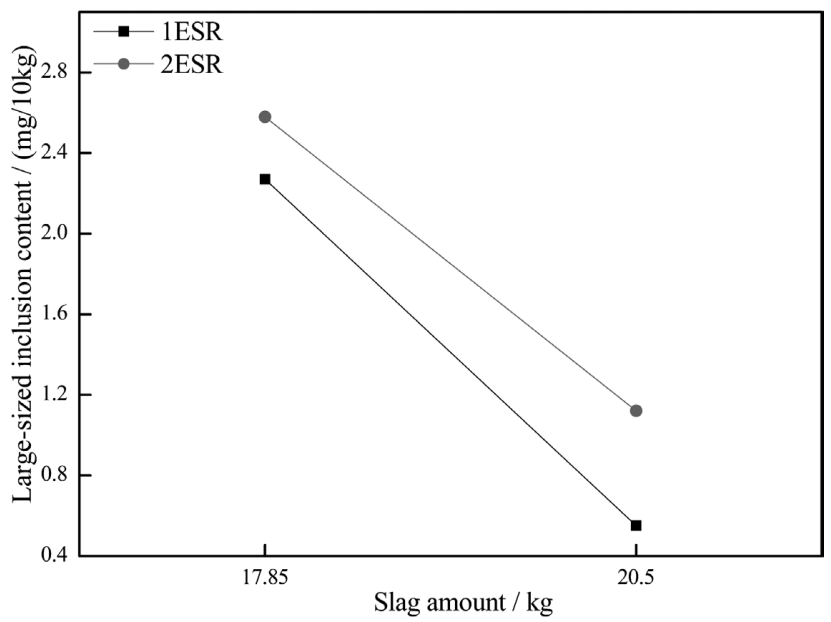

Fig. 4. Effect of slag amount on the large-sized inclusion content in ESR ingots.

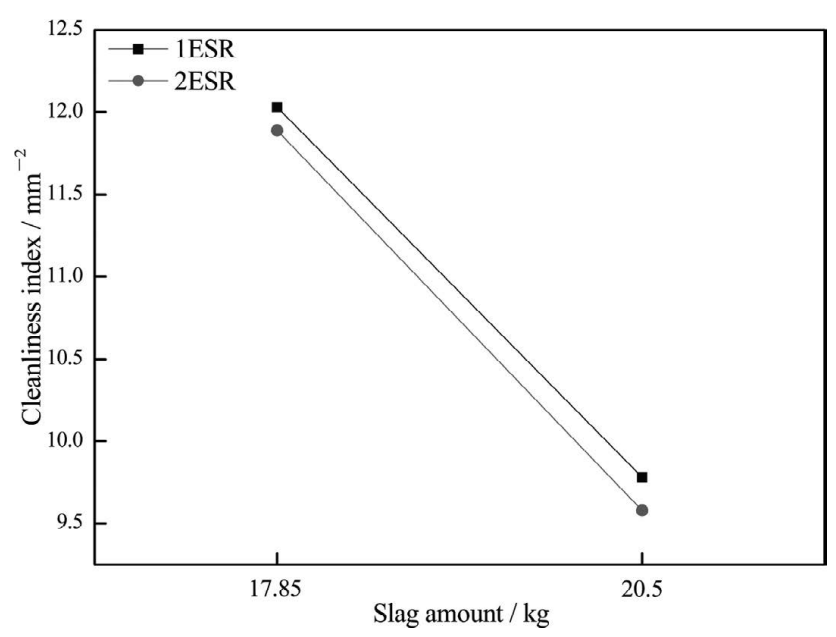

Fig. 5. Effect of slag amount on cleanliness index of ESR ingots.

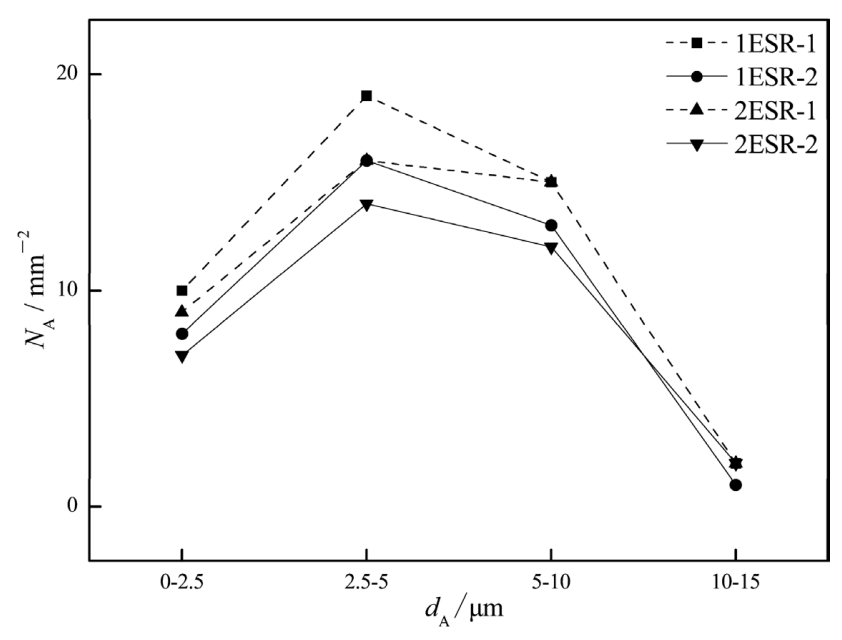

Fig. 6. Number and size distributions of micoscopic inclusions in ESR ingots.

ingot can be increased by about $17.15 \%$ by increasing the slag amount from $17.85 \mathrm{~kg}$ to $20.50 \mathrm{~kg}$.

Figure 6 shows the number and size distributions of microscopic inclusions in ESR ingots. It can be seen from Fig. 6 that the number of microscopic inclusions decreases with the increase of slag amount during ESR process. By comparing the results from the content of large-sized inclusions and the number of microscopic inclusions in each ESR ingot, it can be seen from the above experimental results shown in Figs. 4, 5 and 6 that the decrease ratio of the large-sized inclusions is relatively higher than that of the microscopic inclusions in H13 ESR ingot with the increase of slag amount during remelting. It indicates that the bigger inclusions are more easily to be removed than smaller ones. Similar to the current findings, Bouris et al. ${ }^{23)}$ reported that the larger inclusion can be more easily removed than smaller one.

Therefore, it can be concluded from the above experimental results that removal of inclusion and the cleanliness of the ESR ingot can be promoted by increasing the slag amount during ESR process.

Four reasons may account for this result. The first possible reason may be that less electrode has been oxidized by air due to less surface area surrounding the electrode exposed to area and lower surface temperature of the slag pool under the condition of large slag amount. When the amount of slag is increased, the thickness of the molten slag pool and the electrode immersion depth in slag pool are increased leading to the decrease of the electrode oxidation at high temperature. In additon, it is well known that surface temperature of electrode for large slag amount is lower than that for small slag amount due to greater electrode immersion depth and low surface temperature of slag pool, which lead to different oxidation conditions. Oxide scale caused by oxidation of electrode surface at high temperature is the main reason for the increase of oxygen and inclusion content in steel during ESR. Therefore, electrode surface oxidation is considered to play a greater role according to the above experimental results.

Secondly, the depth of the molten slag pool increases with the increase of slag amount. This indicates that the residence time for the metal droplet travelling through the molten slag pool increases with the increase of slag amount. Thus, the interaction time between metal droplets and molten slag increases with the increase of slag amount, which is conducive to inclusion removal.

The third one is that the flow of the slag pool becomes stronger for large slag amount. Varying the slag amount dramatically affects both the simulated distribution of the Joule heating and thermohydrodynamic behavior of the slag phase; it then logically influences the flow of slag. A two-dimensional model (MeltFlow) was employed to simulate the velocity fields and inclusion motion for a system of electrode, slag and ingot in electroslag remelting processes. Figure 7 provides the velocity fields and inclusion motion in liquid fraction fields of the ingot with different slag amount. Information about the behavior of inclusions and the trajectories of all inclusions at the time instant are noticed in the slag pool and metal pool. Color (red, green, blue, yellow, cyan) is used for trajectories of inclusions of density number $(1,2,3,4,5)$ respectively. Particles originating at three uniformly spaced locations in the metal pool under the electrode shadow just below slag-metal interface. For each density, trajectories for each size are written for all originating locations. The trajectories are written for the left and the right $r-x$ planes around the ingot centerline for easy visualization using layout files. Thus, each type of inclusion has two trajectories written for it. The two zones for each type of particle correspond to the densities, sizes, 


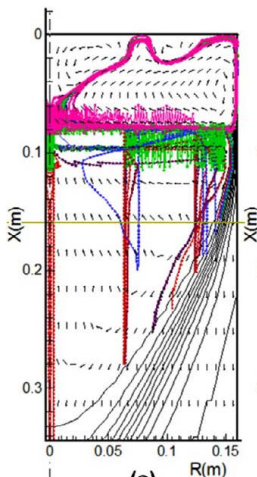

(a)

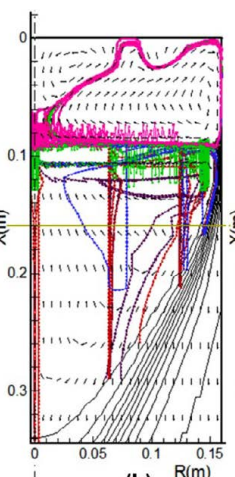

(b)

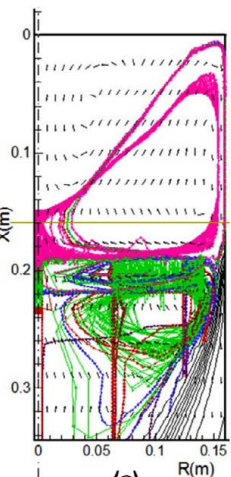

(c)

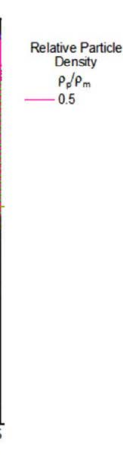

Fig. 7. Velocity fields and inclusion motion in liquid fraction fields of the ingot with different slag amount: (a) $17.85 \mathrm{~kg}$ (80 mm), (b) $20.5 \mathrm{~kg}$ (91 mm), (c) $40 \mathrm{~kg}$ (190 mm). (Online version in color.)

and locations of particles. The motions of inclusions are tracked before they enter the mushy zone or completely dissolve in the molten pool. Inclusions would be expected to experience very different buoyancy and drag forces due to the difference between the slag and molten pools in density and viscosity when they travel through the slag-metal interface. The time required for inclusions to attain their terminal velocities depends on these external forces and their inertia forces. Information about the behavior and trajectories of all inclusions at the time instant are observed in the slag pool and metal pool, as shown in Fig. 7. It can been seen from Fig. 7 that the large light inclusions are expected to vibrate and drift across the slag-metal interface between the slag and the metal pool, while light small inclusions are expected to float into the slag pool and swirl around in it with the flow of slag depending upon their relative particle densities. The relative density of main inclusions calculated from chemical composition in Table 5 is approximately 0.5 . By comparing the density calculated from the chemical composition and the simulation results in Fig. 7, it also can be seen that there is an increasing trend in trajectories of inclusions (i.e., inclusion motion) in slag pool with the increase of slag amount. This is especially the case for inclusions with relative density of 0.5 (i.e., the relative density of the main large-sized inclusions in the ESR ingot).

Figure 8 shows the distribution of the two phases, velocity field and metal pool profile of the ingot with three added slag amount at $5400 \mathrm{~s}$. A liquid sump is expected to be formed with the freezing of metal driven by the heat extracted by the cooling water. The $\mathrm{V}$-shaped metal pool is formed due to the weaker cooling intensity at the bottom of the ingot comparing to that at the edge of the ingot, as shown in Fig. 8. Comparing to the metal pool, the slag pool is more thermodynamically unstable and has stronger velocity field with magnitude larger than that in the molten pool. The predicted velocity vector in the metal pool and slag pool represents the magnitude and direction of the local velocity. It should be mentioned here that no-slip boundary condition on all solid boundaries is used for an implicit treatment of the slag-metal interface which is assumed to be flat. A pair of vortex is observed in each side of the slag pool. One is at the center of the slag pool, while the other is at the vicinity of the slag pool $/$ mold interface. The former is considered to be resulted from the cooling by contact with the electrode

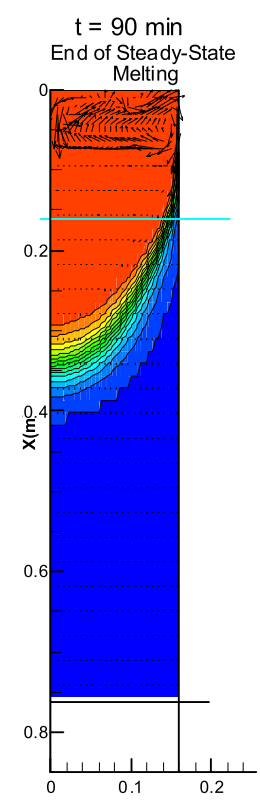

(a)

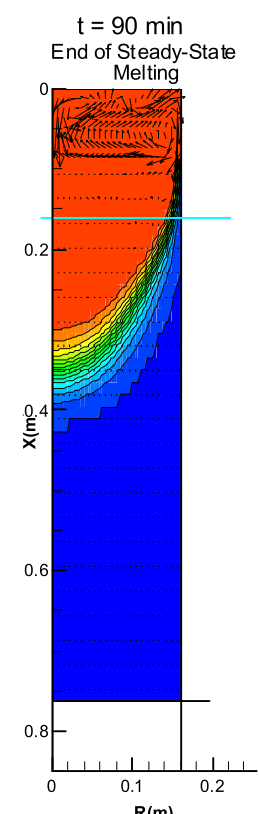

(b)

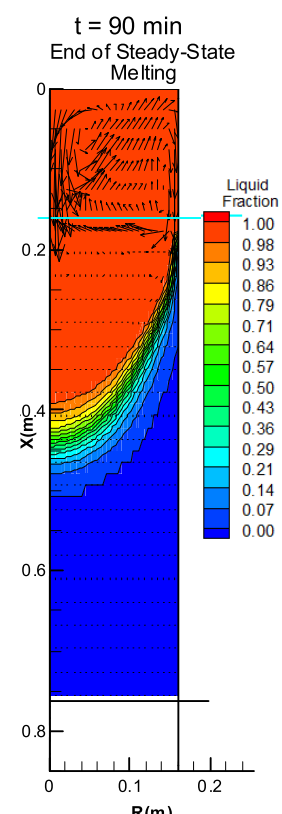

(c)
Fig. 8. Velocity fields and liquid fraction distributions of the ingot with different slag amount at $5400 \mathrm{~s}$ : (a) $17.85 \mathrm{~kg}(80$ $\mathrm{mm})$, (b) $20.5 \mathrm{~kg}$ (91 mm), (c) $40 \mathrm{~kg}$ (190 mm). (Online version in color.)

tip and the divergence of the electric current lines caused by the local predominance of electromagnetic forces (EMF) in the center of the slag. While the latter is created by the natural convective flow caused by a local principal large radial temperature gradient due to the loss of heat extracted by the cooling water at the lateral wall. It can be seen from Fig. 8 that with more slag is added, the downward flows near the mold surface becomes stronger. This is mainly attributed to the loss of more heat extracted by the cooling water at the lateral wall due to the increase of slag pool/ mold interface area caused by the increase of slag amount. Because of the increase of slag amount, the metal and slag flow faster, resulting in a more vigorous circulation cell, and the maximal velocity increases from $0.0482 \mathrm{~m} \mathrm{~s}^{-1}$ to 0.0532 $\mathrm{m} \mathrm{s}^{-1}$. The momentum and heat transfer are reinforced by the increase of slag amount. Thus the thermohydrodynamic conditions of the slag pool is expected to be improved by the stronger natural convective flow, which is beneficial for inclusion removal. Therefore, it can be inferred from Figs. 7 and 8 that the mass transfer, reaction kinetics and chemical interactions between inclusions and slag is promoted by the stronger natural convective flow with the increase of slag amount, which is conducive to inclusion removal.

Moreover, it can be inferred from Fig. 8 that the liquid metal pool is shallowed for large slag amount. Varying the slag amount dramatically affects both the effect of the Joule heating and heat extracted by the cooling water; it then logically influences the depth of liquid metal pool. Concerning the metal pool profile, metal pool depth results from the combined action of Joule heating and cooling by contacting with the water-cooled mold.

The metal pool depth varies during remelting with changes in the operating conditions, while it is always determined by the combination and competition between these two actions, as indicated in Fig. 8, in which the distribution 
of the two phases, velocity field and metal pool profile of the ingot with three added slag amount, at $5400 \mathrm{~s}$ of remelting, are illustrated. In the close vicinity of the slag/pool interface, the metal flows along the radial direction toward lateral wall and, thereafter, from there downwards driven by the combined action of Lorentz force, molten slag pressure and temperature gradient. Most of the heat is thus taken away from the metal flow by the cooling water resulted from its interaction with the water-cooled mold. As a result, the metal gets "colder" and denser. Afterwards, the denser metal flows downwards the bottom along the slanting solidification front. Finally, a metal pool is expected to be formed as the melting proceeds due to the srtonger cooling action of the lateral wall than that of the bottom. In the liquid pool, the fluid motion is low which is mainly driven by buoyancy, due to the weaker cooling along the slanting solidification front than that along the lateral wall.

Clearly, the larger the slag amount, the stronger the Joule heating effect. This is mainly linked to the fact that, for a constant electrical power consumption, the power applied in the slag pool increases with an increase in the slag amount. Figure 9 shows the circuit diagram of ESR process. Wherein, $R_{1}$ is constant; $R_{2}$ is determined by the attributes of electrode; $\mathrm{R}_{3}$ is determined by slag composition and slag amount (i.e., the depth of liquid slag pool); $\mathrm{R}_{4}$ is determined by the characteristics of the ESR ingot. As it can be seen from Fig. 9, the value of the slag resistance is determined by the slag amount. Actually, the slag resistance is a direct consequence of electrical current flows the slag pool, which can be roughly calculated by the following classical equation,

$$
R_{\text {slag }}=\frac{h_{\text {slag }}}{\sigma_{\text {slag }} S}
$$

where $h_{\text {slag }}$ is the height of the slag layer, $\sigma_{\text {slag }}$ is electrical conductivity of the slag, $S$ is the cross-sectional area of slag layer between the electrode and the ingot. Because the surface through which the electrical current flows is the same in all cases, the only parameter modified by a variation in the slag amount is the slag height. Therefore, the slag resistance increases hyperbolically when the slag amount increases

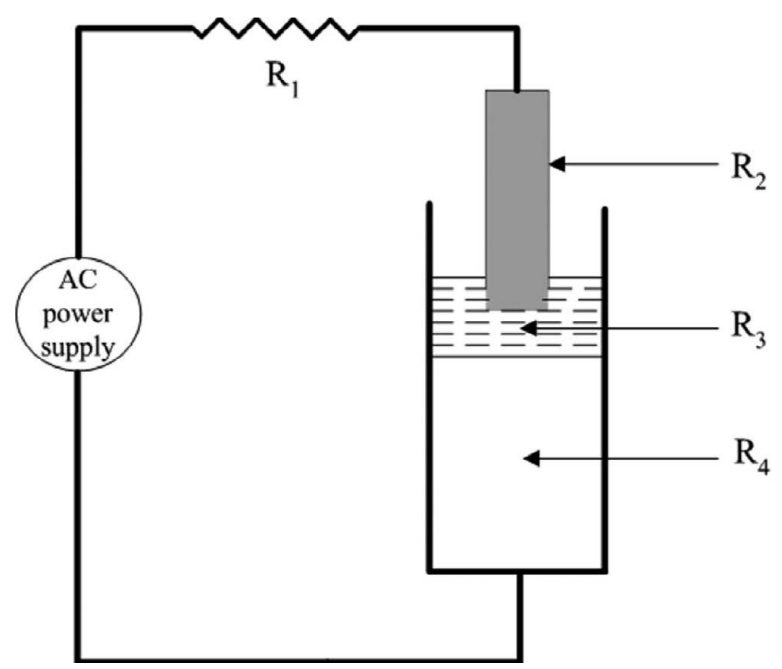

Fig. 9. Circuit diagram of the ESR process. Note: R1 - line resistance; R2 - electrode resistance; R3 - liquid slag resistance; R4 - ESR ingot resistance. in ESR process. It also can be seen from Fig. 9, the value of the power applied in the slag pool is determined by the slag resistance under the condition of the same electrical power consumption in the circuit diagram. Therefore, it can be inferred that the Joule heating of slag pool profoundly increases with the increase of slag amount when the power system is maintained constant during ESR process. However, the interaction between the slag pool and water-cooled mold also becomes stronger due to the increase of the slag/ mold interface area, and the amount of heat taken away by the cooling water outweighs that created by the newly generated Joule heating. Consequently, the liquid metal pool becomes "colder" with the increase of slag amount leading to the decrease of the metal pool depth. Thus the molten pool is expected to become shallower with the increase of slag amount, which is conducive to inclusion removal.

However, the amount of slag is not the bigger the better. The selection of slag amount is also related to the given material and ingot size. It has been widely accepted that the selection of slag amount used for the ESR process is mainly based on the the following empirical formula, ${ }^{24}$

$$
\begin{gathered}
G_{\text {slag }}=(4 \%-5 \%) G_{\text {ingot }} \\
G_{\text {slag }}=S_{\text {mould }} H_{\text {slag }} \rho_{\text {slag }} \\
H_{\text {slag }}=f_{\text {slag }} D_{\text {mould }} \ldots . .
\end{gathered}
$$

where $G_{\text {slag }}$ is the amount of slag, $G_{\text {ingot }}$ is the weight of ingot, $S_{\text {mould }}$ is the cross-sectional area of slag layer, $\rho_{\text {slag }}$ is the density of slag, $H_{\text {slag }}$ is the height of slag layer, $f_{\text {slag }}$ is the coefficient of the slag height, $D_{\text {mould }}$ is the diameter of mould. The calculation value of the slag amount derived from the empirical formula can be used as a reference value, whereas the optimum slag amount must be determined according to the used equipment and actual conditions of the local electric power system.

From the above analysis, it can be found that in the conditions of a certain electric power system and process permitting under the current ESR process, the appropriate increase of slag amount from $17.85 \mathrm{~kg}$ to $20.5 \mathrm{~kg}$ considering the relationship between slag amount and mould size can reduce the electrode oxidation at high temperature and promote inclusion removal in ESR process, and thus help to improve the ESR ingot cleanliness.

\subsection{Effect of Remelting Current on the Content and Removal of Inclusion}

Figure 10 shows the effect of current on the large-sized inclusion content in ESR ingots. It is clear that: (i) in the case of the remelting performed with the increased current of 4.5-5.5 kA (Exp. No. 1T-4), the content of large-sized inclusion can be reduced by $54.44 \%$ from the original inclusion amount, i.e., $2.59 \mathrm{mg} / 10 \mathrm{~kg}$, in the ESR ingot 1ESR-3 (Exp. No. 1T-3) to $1.18 \mathrm{mg} / 10 \mathrm{~kg}$ in the ESR ingot 1ESR-4 (Exp. No. 1T-4); (ii) in the case of the remelting performed with the current of 4.5-5.5 kA (Exp. No. 2T-4), the content of large-sized inclusion can be reduced by $48.32 \%$ from the original inclusion amount, i.e., $2.98 \mathrm{mg} / 10 \mathrm{~kg}$, in the ESR ingot 2ESR-3 (Exp. No. 2T-3) to $1.54 \mathrm{mg} / 10 \mathrm{~kg}$ in the ESR ingot 2ESR-4 (Exp. No. 2T-4). It was confirmed on the basis of experimental results that the content of large- 


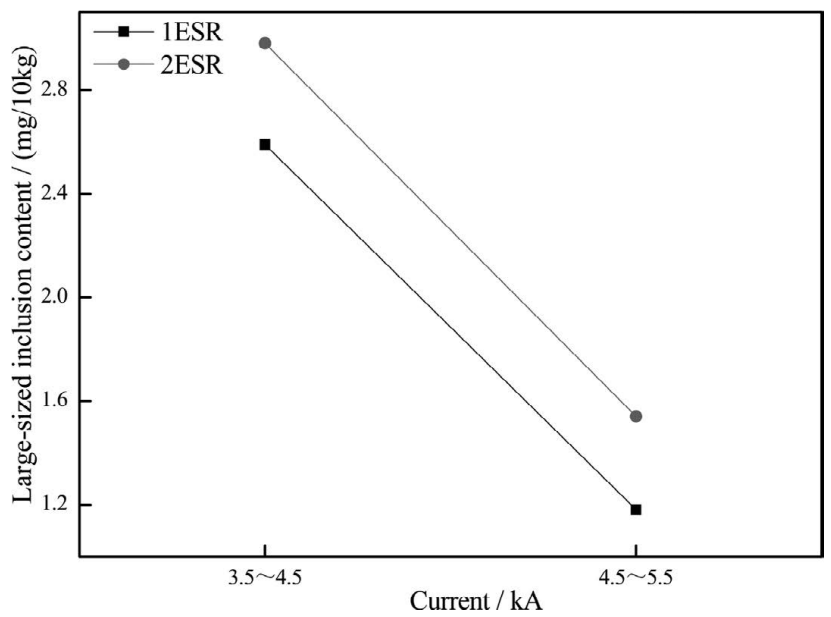

Fig. 10. Effect of current on the large-sized inclusion content in ESR ingots.

sized inclusions of H13 ESR ingot can be reduced by about $51.38 \%$ through increasing the current from 3.5-4.5 kA to 4.5-5.5 kA. Therefore, it can be concluded that the inclusion removal was promoted with the increase of remelting current during ESR process.

The removal of non-metallic inclusion occurred mainly during liquid metal film formation, its gradual coalescence into droplet at the consumable electrode tip and subsequent falling through the slag, ${ }^{24)}$ especially the earlier stage of droplets formation where the removal efficiency of nonmetallic inclusion is more pronounced due to the following reasons: First, as current flows from the electrode, through the slag to the ingot, the electrode tip is heated to a high temperature above the melting point of the electrode, even up to $2000^{\circ} \mathrm{C}^{25)}$ Thus original solid inclusions in consumable electrode can be generally turned into liquid, and thereafter absorbed by the slag at slag-metal pool interface; Second, an extreme thin layer of liquid metal film (normally 50-200 $\left.\mu \mathrm{m}^{11)}\right)$ is expected to be formed at the consumable electrode tip resulted in the relatively high ratio of surface/interface area to volume between the slag and liquid metal film ${ }^{26,27)}$ and, hence, the relatively larger contact area between metal and slag, thus the inclusion particles stand greater chance of interacting with molten slag in liquid metal film; Third, the formation of liquid metal film and subsequently coalescence of droplets took much longer time than molten drops falling through the slag layer. ${ }^{25)}$ Therefore, it can be concluded that high chemical reaction temperature, large contact area between metal and slag, long chemical reaction time in this stage is favorable for the chemical reaction dynamics of inclusion removal.

Based on the above considerations, three reasons may account for this result. The first possible reason may be that the interaction between molten steel and slag is more sufficient for large remelting current. Wang et al. ${ }^{28)}$ built a transparent experimental model to visualize the ESR process, and investigated the effects of different strength of the remelting current on the droplet evolution. Their experimental results show that the tips become sharper and sharper with the increase of the remelting current; also, the metal neck becomes shorter and the main droplet becomes smaller with the increase of the remelting current as shown in their experimental results. Predictably, the average diameter of droplets decreases with the increase of remelting current during ESR process according to their experimental results. This is mainly due to the fact that the interfacial tension between slag and steel decreases with the increase of slag temperature caused by the increase of remelting current. ${ }^{29}$ In additon, the droplet radius decreases with the decrease of the interfacial tension between slag and steel according to the equation given by Campbell. ${ }^{30)}$ Consequently, this decrease in diameter will result in the increase of slag/ droplet interface area. Moreover, it can be inferred that less droplets drip simultaneously due to the more pointed electrode tip under large remelting current condition. Thus the number of droplets for large remelting current is less than that for small remelting current condition, the size of droplets is smaller than that for small remelting current; then interaction between slag and droplets is more sufficient for the large remelting current condition. Furthermore, according to the classical work of Wang et al that the surface area of electrode tip immersed in slag pool increases with the increase of current in ESR process. ${ }^{24)}$ This is due to the fact that the area of the electrode in contact with the slag increases with the increase of current. ${ }^{31)}$ Consequently, this increase in surface area of electrode tip will result in the increase of liquid metal film-slag interface. Based on the above discussions, it can be concluded that the average radius of droplets decreases and the area of liquid metal film-slag interface increases with the increase of remelting current. This fact indicates that the contact area between moten steel and slag increases with the increase of remelting current during ESR process, which is beneficial to the chemical reaction dynamics of inclusion removal.

The second one is that the flow in the middle of the slag pool becomes stronger for large remelting current. Varying the remelting current dramatically affects both the simulated distribution of the velocity field and the electromagnetic force (EMF) and thermohydrodynamic behavior of the slag phase; it then logically influences the flow of slag pool. A two-dimensional model (MeltFlow) was employed to simulate the velocity field and solidification for a system of electrode, slag and ingot in electroslag remelting processes. Figure 11 shows the distribution of the two phases, velocity field and solidification of the ingot with three applied remelting current at $5400 \mathrm{~s}$. A pair of vortex is observed in each side of the slag pool. One is at the center of the slag pool, while the other is at the vicinity of the slag pool/mold interface. The former is considered to be resulted from the cooling by contact with the electrode tip and the divergence of the electric current lines induced by the local predominance of electromagnetic forces (EMF) in the center of the slag. While the latter is created by the natural convective flow caused by a local principal large radial temperature gradient due to the loss of heat extracted by the cooling water at the lateral wall. It can be seen from Fig. 11 that with more current is applied, the flow in the middle of the slag pool becomes stronger, and the maximal downward velocity increases from $0.0165 \mathrm{~m} \mathrm{~s}^{-1}$ to $0.0169 \mathrm{~m} \mathrm{~s}^{-1}$. This fact indicates that the renewal rate of the metal film surface due to the washing by slag flow would become stronger with the increase of remelting current. In addition, the migration speed of inclusions from the inside of liquid metal to the steel-slag interface is determined by the renewal rate of the 


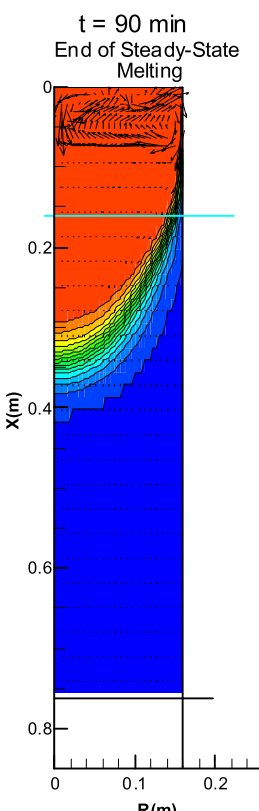

(a)

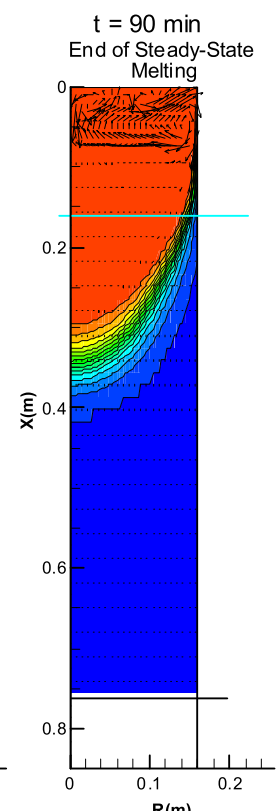

(b)

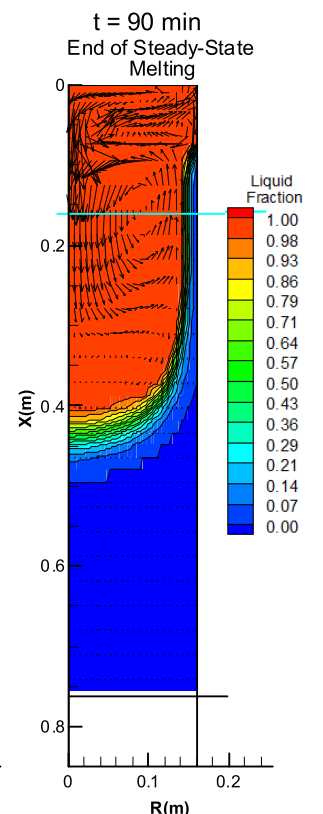

(c)
Fig. 11. Velocity fields and liquid fraction distributions of the ingot with different applied remelting current at $5400 \mathrm{~s}$ : (a) $4000 \mathrm{~A}$, (b) $5000 \mathrm{~A}$, (c) $10000 \mathrm{~A}$. (Online version in color.)

metal film surface during the droplet formation period at the electrode tip. ${ }^{32)}$ Thus, it is expected that the migration speed of inclusions from liquid metal internal to the steel-slag interface would be quickened with more current is applied. Consequently, the interaction frequency between slag and inclusion in liquid metal film (i.e., the opportunity for inclusions to directly contact with molten slag) increases with the increase of current, which is beneficial to inclusion removal.

The third one is that the interfacial tension is lower for large remelting current. Obviously, the temperature of slag pool increases with the increase of remelting current. Thus, both the interfacial tension between slag and steel and that between slag and inclusion decrease with the increase of remelting current as discussed above, which is conducive to inclusion removal at the steel-slag interface.

However, the remelting current is not the bigger the better. With further increase of remelting current, it is expected that the dynamic conditions for inclusion flotation during ESR process would become poor if the the remelting current is too large. The two-dimensional model (MeltFlow) was employed to simulate the velocity fields and inclusion motion for a system of electrode, slag and ingot in electroslag remelting processes. Figure $\mathbf{1 2}$ provides the velocity fields and inclusion motion in liquid fraction fields with different applied remelting current. Information about the behavior of inclusions and the trajectories of all inclusions at the time instant are noticed in the slag pool and metal pool. Color (red, green, blue, yellow, cyan) is used for trajectories of inclusions of density number $(1,2,3,4,5)$ respectively. Particles originating at three uniformly spaced locations in the metal pool under the electrode shadow just below slagmetal interface. For each density, trajectories for each size are written for all originating locations. The trajectories are written for the left and the right $r-x$ planes around the ingot centerline for easy visualization using layout files. Thus,

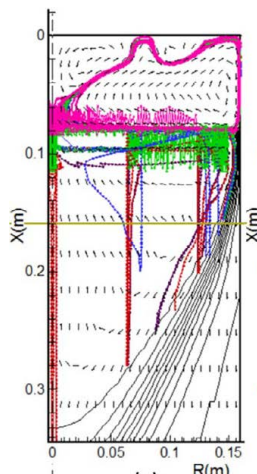

(a)

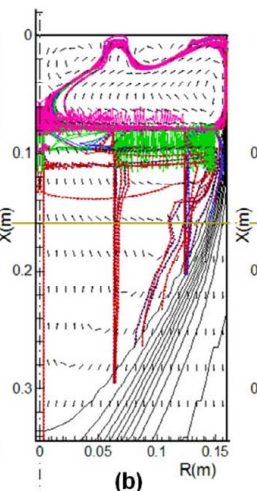

(b)

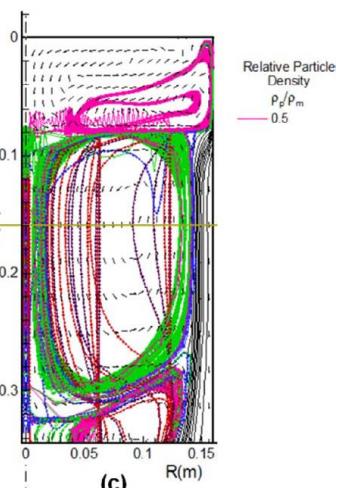

(c)
Fig. 12. Velocity fields and inclusion motion in liquid fraction fields of the ingot with different applied remelting current: (a) $4000 \mathrm{~A}$, (b) $5000 \mathrm{~A}$, (c) $10000 \mathrm{~A}$. (Online version in color.)

each type of inclusion has two trajectories written for it. The two zones for each type of particle correspond to the densities, sizes, and locations of particles. The motions of inclusions are tracked before they enter the mushy zone or completely dissolve in the molten pool. Information about the behavior and trajectories of all inclusions at the time instant are observed in the slag pool and metal pool, as shown in Fig. 12. By comparing the density calculated from the chemical composition and the simulation results in Fig. 12 , It can be seen that a large proportion of the inclusion with relative density of 0.5 (i.e., the relative density of the main large-sized inclusions in the ESR ingot) would sink into the metal pool and can not float to the steel/slag interface as shown in the case of $10000 \mathrm{~A}$. It can be inferred that those inclusions would be left in ESR ingot due to the rapid advance of the solidifying front during solidification.

This might be attributed to the fact that, with an excessive amount of remelting current application, the molten pool is expected to be changed into deep and wide concave shape. Wang et al. investigated the effect of the current on the metal pool depth, and they found that a deeper metal pool is formed and the maximum metal pool depth increases with the increase of current. ${ }^{33)}$ It should be noted that the steel liquid is solidified from the bottom up and there is always a horizontal component of solidification during electroslag remelting process. When the molten pool is too deep and wide concave shape, the local crystal growth direction of the steel liquid is nearly perpendicular to the mold wall and the ingot axis and, hence, the gravitational field, ${ }^{34)}$ especially at the lower part of the metal pool. Thus inclusions would be wrapped into the molten pool by dendrites in converging columnar grains at the solidification front, ${ }^{35)}$ which is adverse to the flotation removal of inclusions. Therefore, the appropriate increase of current from $4000 \mathrm{~A}$ to $5000 \mathrm{~A}$ can achieve better dynamic conditions for inclusion removal during ESR process.

\section{Conclusions}

The effect of operating conditions (i.e., slag amount and current) on the steel cleanliness, content and removal ratio of inclusions, especially those large-sized inclusions during electroslag remelting of $\mathrm{H} 13$ die steel was investigated. The mechanisms of inclusion removal during ESR process were 
also discussed, based on experimental results along with thermohydrodynamic analysis. To sum, important conclusions can be drawn as follows:

(1) When the slag amount was increased from 17.85 $\mathrm{kg}$ to $20.50 \mathrm{~kg}$, the content of large-sized inclusions in ESR ingot was decreased by approximately $66.18 \%$, the number of inclusions decreases and the cleanliness index of H13 ESR ingot was decreased by about $17.15 \%$. The influence of the increasing of slag amount on the decrease ratio of bigger inclusions was more pronounced than it was for the small inclusions (radius of $0-15 \mu \mathrm{m}$ ). Under the current ESR process, it is suggested that the appropriate increase of the slag amount from $17.85 \mathrm{~kg}$ to $20.5 \mathrm{~kg}$ can promote the inclusion removal and reduce the electrode oxidation at high temperature, thus improve the cleanliness of $\mathrm{H} 13$ ESR ingots.

(2) Because of the increase of slag amount, the metal and slag flow faster and the maximal velocity increases from $0.0482 \mathrm{~m} \mathrm{~s}^{-1}$ to $0.0532 \mathrm{~m} \mathrm{~s}^{-1}$, thus the momentum and heat transfer are reinforced by the increase of slag amount. There is an increasing trend in trajectories of inclusions (i.e., inclusion motion) in slag pool resulted from the stronger natural convective flow with the increase of slag amount, which is beneficial for the inclusion removal.

(3) When the average current was raised from $4 \mathrm{kA}$ to 5 $\mathrm{kA}$, the content of large-sized inclusions in H13 ESR ingot was decreased by about $51.38 \%$. Because of the increasing of current, the flow in the middle of the slag pool becomes stronger and the maximal downward velocity increases from $0.0165 \mathrm{~m} \mathrm{~s}^{-1}$ to $0.0169 \mathrm{~m} \mathrm{~s}^{-1}$, thus the washing of metal film surface by slag flow is reinforced by the increase of current. There is an increasing trend in the renewal rate of the metal film surface due to the stronger washing by slag flow with the increase of remelting current, which can promote the inclusion removal.

(4) A large proportion of the inclusion with relative density of 0.5 (i.e., the relative density of the main largesized inclusions in the ESR ingot) would sink into the metal pool and can not float to the steel/slag interface in the case of $10 \mathrm{kA}$. Under the current ESR process, it is suggested that the appropriate increase of the remelting current from $4 \mathrm{kA}$ to $5 \mathrm{kA}$ can promote the inclusion removal, thus improve the cleanliness of H13 ESR ingots.

\section{Acknowledgments}

Sincere appreciation is given to the National Natural Science Foundation of China (No. 51374022).

\section{REFERENCES}

1) L. F. Zhang and B. G. Thomas: Metall. Mater. Trans. B, 37B (2006), 733.

2) E. Castro-Cedeño, M. Herrera-Trejo, M. Castro-Román, F. Castro-Uresti and M. López-Cornejo: Metall. Mater. Trans. B, 47B (2016), 1613.

3) L. Z. Wang, S. F. Yang, J. S. Li, T. Wu, W. Liu and J. Z. Xiong: Metall. Mater. Trans. B, 47B (2016), 99.

4) L. F. Zhang and B. G. Thomas: ISIJ Int., 43 (2003), 271.

5) J. Z. Li, M. Jiang, X. F. He, W. Sun and X. H. Wang: Metall. Mater. Trans. B, 47B (2015), 2386.

6) J. Yao, X. H. Qu, X. B. He and L. Zhang: Int. J. Miner. Metall. Mater., 19 (2012), 608.

7) V. Weber, A. Jardy, B. Dussoubs, D. Ablitzer, S. Rybéron, V. Schmitt, S. Hans and H. Poisson: Metall. Mater. Trans. B, 40B (2009), 271.

8) S. K. Maity, N. B. Ballal, G. Goldhahn and R. Kawalla: ISIJ Int., 49 (2009), 902

9) B. K. Li, F. Wang and F. Tsukihashi: ISIJ Int., 52 (2012), 1289.

10) X. H. Wang and Y. Li: Metall. Mater. Trans. B, 46B (2015), 1837.

11) M. E. Fraser and A. Mitchell: Ironmaking Steelmaking, 3 (1976), 281.

12) J. D. Busch, J. J. Debarbadillo and M. J. M. Krane: Metall. Mater. Trans. A, 44A (2013), 5295.

13) W. Li, W. Wang, Y. Hu and Y. Chen: Metall. Mater. Trans. B, 43B (2012), 276

14) L. Chang, X. Shi, H. Yang and Z. Li: J. Iron Steel Res. Int., 16 (2009), 7.

15) M. Kawakami, T. Takenaka and M. Ishikawa: Ironmaking Steelmaking, 29 (2002), 287.

16) Y. W. Dong, Z. H. Jiang, Y. L. Cao, A. Yu and D. Hou: Metall. Mater. Trans. B, 45B (2014), 1315.

17) A. Paar, R. Schneider, P. Zeller, G. Reiter, S. Paul and P. Würzinger: Steel Res. Int., 87 (2014), 570.

18) G. Du, J. Li, Z. B. Wang and C. B. Shi: Proc. Iron \& Steel Technology Conf., Association for Iron \& Steel Technology, Warrendale, PA, (2015), 2215.

19) L. Zhang, S. Tanighchi and K. Cai: Metall. Mater. Trans. B, 31B (2000), 253.

20) K. M. Kelkar, S. V. Patankar and A. Mitchell: Proc. Int. Symp. Liquid Metal Processing and Casting, Springer International Publishing, Berlin, (2005), 137.

21) K. M. Kelkar, S. V. Patankar, S. K. Srivatsa, R. S. Minisandram, D. G. Evans, J. J. deBarbadillo, R. H. Smith, R. C. Helmink, A. Mitchell and H. A. Sizek: Proc. Int. Symp. Liquid Metal Processing and Casting, Springer International Publishing, Berlin, (2013), 1.

22) A. D. Patel and K. M. Kelkar: Proc. 12th Int. Conf. Modeling of Casting, Welding, Adv. Solidification Processes, TMS, Warrendale, PA, (2009), 69.

23) D. Bouris and G. Bergeles: Metall. Mater. Trans. B, 29B (1998), 641.

24) Z. B. Li: Electroslag Metallurgy Theory and Practice, Metallurgical Industry Press, Beijing, (2010), 7.

$25)$ Z. B. Li, W. H. Zhou and Y. D. Li: Iron Steel, 15 (1980), 20.

26) E. Plöckinger: J. Iron Steel Inst., 211 (1973), 533.

27) W. Holzgruber, K. Petersen and P. E. Schneider: Trans. Int. Vacuum Metallurgy Conf., American Vacuum Society, New York, (1968), 499.

28) H. Wang, Y. B. Zhong, Q. Li, Y. P. Yi, W. L. Ren, Z. S. Lei and Z. M. Ren: ISIJ Int., 56 (2016), 255.

29) L. Rao, Y. Zhang and M. P. Geng: Foundry Technol., 31 (2010), 154.

30) J. Campbell: JOM, 22 (1970), 23.

31) D. K. Melgaard, R. L. Williamson and J. J. Beaman: JOM, 50 (1998), 13.

32) J. Fu: Acta Metall. Sin., 15 (1979), 526.

33) Q. Wang, F. S. Qi, F. Wang and B. K. Li: Int. J. Precis. Eng. Manuf., 16 (2015), 2467.

34) R. Mehrabian, M. Keane and M. C. Flemings: Metall. Trans., 1 (1970), 1209.

35) X. Geng, Z. H. Jiang, F. B. Liu and L. K. Liang: Iron Steel, 44 (2009), 42 . 